\section{Stability of Extemporaneously Compounded Tacrolimus in Glass Bottles and Plastic Syringes}

Tacrolimus is an immunosuppressive agent used to prevent allograph rejection. ${ }^{1,2}$ It is available as immediate-release (0.5-, 1-, and 5-mg) or extended-release (0.5-, 1-, 3-, and 5-mg) capsules. The stability of extemporaneous oral suspensions in Ora-Plus/Ora-Sweet and Ora-Plus/syrup has been reported previously. ${ }^{3-6}$ The current study was undertaken to evaluate the stability of tacrolimus in Oral Mix vehicle.

Tacrolimus suspensions $(0.5 \mathrm{mg} / \mathrm{mL})$ were prepared from bulk powder and from capsules. For bulk powder preparations, tacrolimus USP (117.6 mg; Medisca Pharmaceutique Inc, Montréal, Quebec; lot 48905/A, expiry May 2015; equivalent to $115 \mathrm{mg}$ tacrolimus anhydrous) was wetted with polysorbate 80 (250 $\mu \mathrm{L}$, Tween 80; Sigma Aldrich, Oakville, Ontario; lot MKBJ0197V) and Oral Mix vehicle (500 $\mu \mathrm{L}$; Medisca Pharmaceutique Inc; lot I074/A, expiry February 2015) using a mortar and pestle. Oral Mix was then progressively added to achieve the required concentration $(0.5 \mathrm{mg} / \mathrm{mL}$, final volume $230 \mathrm{~mL})$. Tacrolimus suspensions from capsules were similarly prepared, without polysorbate 80 (content of $23 \times 5$-mg Prograf capsules, Astellas Pharma Canada, Inc, Markham, Ontario; lot 044014, expiry April 2015; final volume $230 \mathrm{~mL}$ in Oral Mix).

Each preparation was packaged in amber glass bottles $(6 \times 30-\mathrm{mL}$ fill volume; $50-\mathrm{mL}$ Wheaton type 1 bottles, Medisca Pharmaceutique Inc, lot 24908/A) and amber plastic syringes ( $48 \times 1$-mL fill volume; PreciseDose Dispenser, lot 46968/C, with tip cap, lot 55052/A, Medisca Pharmaceutique Inc). Preparations were stored at $5^{\circ} \mathrm{C}$ or $25^{\circ} \mathrm{C}$ for up to 90 days. Three bottles were stored at each temperature, and an aliquot was removed from each bottle at each time point for analysis. Half of the syringes were stored at each temperature, and 3 syringes per temperature were used for analysis on each study day.

On each study day, all samples were examined for colour and odour, and $\mathrm{pH}$ was measured using a pH 211 meter (Hanna

Table 1. Chemical Stability of Tacrolimus Formulation Prepared from Bulk Powder*

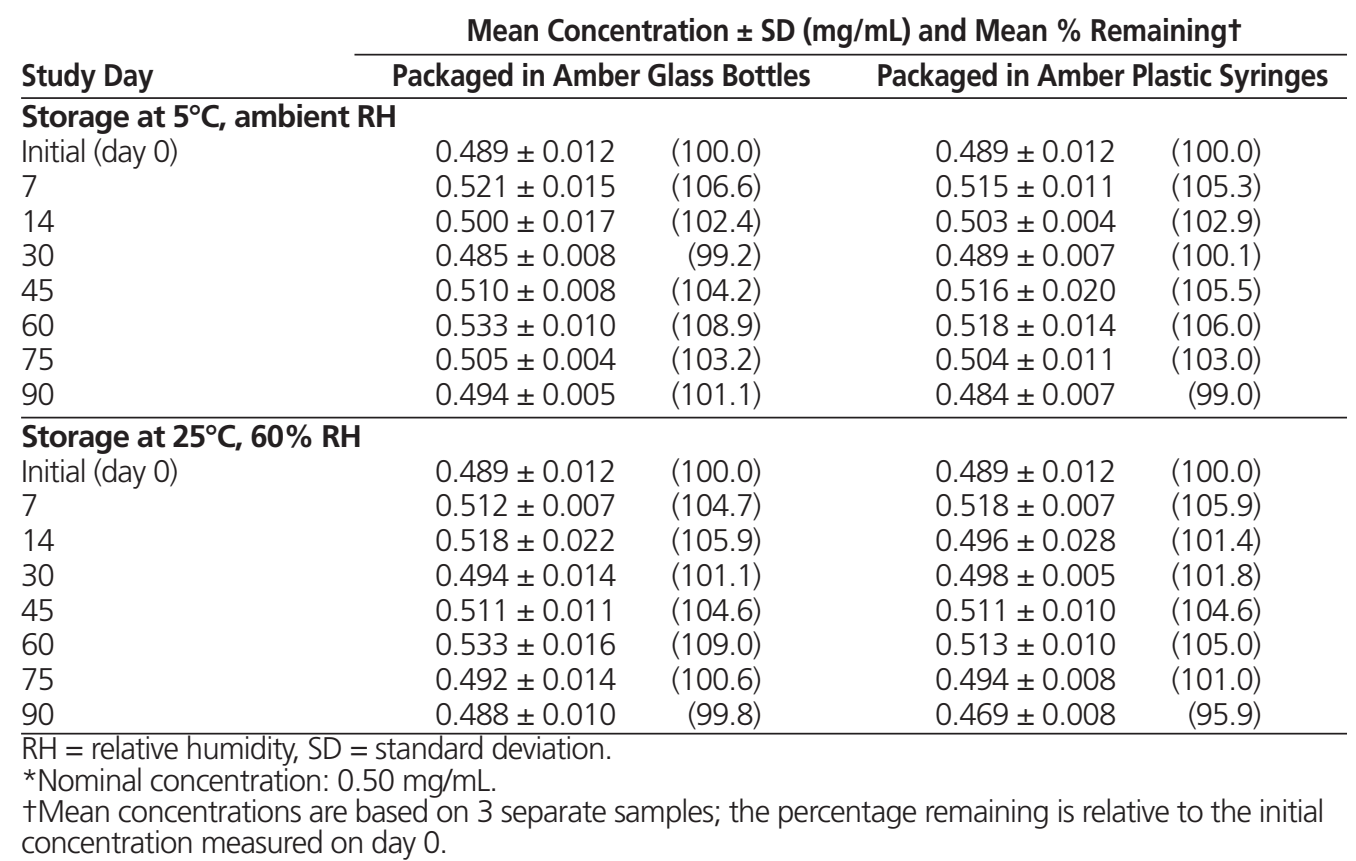


Instruments, Montréal, Quebec). Tacrolimus concentration was then assayed by high-performance liquid chromatography with ultraviolet detection (HPLC-UV).

For the HPLC-UV analysis, each sample $(100 \mu \mathrm{L})$ was first diluted with acetonitrile $(400 \mu \mathrm{L}, \mathrm{HPLC}$-grade, Fisher Scientific, Ottawa, Ontario; lot 141693), vigorously vortexed (20 s, Vortex Genie 2, Fisher Scientific), and centrifuged (13000 rpm for $10 \mathrm{~min}$; model 5424 centrifuge, Eppendorf Canada, Mississauga, Ontario). The mixture separated into a lower phase $(12 \% \mathrm{v} / \mathrm{v})$ and an upper phase $(88 \% \mathrm{v} / \mathrm{v})$. An aliquot of the supernatant $(150 \mu \mathrm{L})$ was then diluted with purified water $(150 \mu \mathrm{L}$; Milli-Q Synthesis A10 system, Millipore, Etobicoke, Ontario) and analyzed by HPLC-UV.

The HPLC system (Prominence UFLC, Shimadzu, Laval, Quebec) consisted of a degasser, a binary pump ( $0.9 \mathrm{~mL} / \mathrm{min})$, a photodiode array detector $(210 \mathrm{~nm})$, a refrigerated autosampler $\left(5^{\circ} \mathrm{C}\right)$, a column oven $\left(50^{\circ} \mathrm{C}\right)$, and a Kinetex XB C18 column $(4.6 \times 100 \mathrm{~mm}, 5 \mu \mathrm{m}$, Phenomenex, Torrance, California; lot 5705-26). The mobile phase consisted of acetonitrile and water (30:70).

Tacrolimus standards $(0.6,0.5,0.4,0.3$, and $0.2 \mathrm{mg} / \mathrm{mL})$ were prepared in Oral Mix vehicle for validation of the method. Injection samples were prepared from these standard samples as described above and immediately analyzed by HPLC-UV (triplicate preparations, triplicate injection samples, all repeated on days 0,3 , and 7). The tacrolimus peak eluted at about $3.8 \mathrm{~min}$. The coefficient of regression $\left(r^{2}\right)$ of the calibration curve was at least 0.998. The intraday coefficient of variation calculated for triplicate injection samples was not more than $0.6 \%$ in all cases. The intraday coefficient of variation calculated between sample preparations at the target concentration was not more than 3.3\%. Similarly, the interday coefficient of variation at the target concentration was $3.1 \%$.

A stress degradation study was performed using 1:1 mixtures of the $0.5 \mathrm{mg} / \mathrm{mL}$ standard sample with water, hydrochloric acid (HCl) $0.1 \mathrm{~mol} / \mathrm{L}$, sodium hydroxide $(\mathrm{NaOH}) 0.1 \mathrm{~mol} / \mathrm{L}$, and hydrogen peroxide $\left(\mathrm{H}_{2} \mathrm{O}_{2}\right) 3 \%$ (incubated at $60^{\circ} \mathrm{C}$ for $4 \mathrm{~h}$ ). Samples for HPLC injection were prepared as described above. Degradation of tacrolimus was observed for all conditions (recovery $58.7 \%$ in water, $89.6 \%$ in $\mathrm{HCl}, 41.0 \%$ in $\mathrm{NaOH}$, and $64.1 \%$ in $\mathrm{H}_{2} \mathrm{O}_{2}$ ). No peak overlap or signal interactions with excipients or with degradation products were observed.

On each study day, all suspensions were easily resuspended, no changes in colour or odour were noticed, and the $\mathrm{pH}$ remained constant at 4.4. The mean tacrolimus concentration was not less than $90.0 \%$ of initial concentration for each tested condition (Tables 1 and 2). One measured value was $111.8 \%$ after 60 days of storage, but it is believed that analytical error was responsible for this high value, as it was not repeated on days 75 and 90 (Table 2).

All tacrolimus suspensions $(0.5 \mathrm{mg} / \mathrm{mL}$ in Oral Mix, prepared from capsules or bulk powder, stored in glass bottles or plastic syringes at $5^{\circ} \mathrm{C}$ or $25^{\circ} \mathrm{C}$ ) were stable for at least 90 days. These results compare favourably with those for a previously reported tacrolimus suspension in a mixture of Ora-Plus and simple syrup, which was stable for at least 56 days. $^{6}$

Table 2. Chemical Stability of Tacrolimus Formulation Prepared from Tablets*

\begin{tabular}{lrrrr} 
& \multicolumn{4}{c}{ Mean Concentration \pm SD $(\mathbf{m g} / \mathbf{m L})$ and Mean \% Remainingt } \\
\cline { 2 - 5 } Study Day & \multicolumn{3}{c}{ Packaged in Amber Glass Bottles } & Packaged in Amber Plastic Syringes \\
\hline Storage at $\mathbf{5}^{\circ} \mathbf{C}$, ambient RH & & & & \\
Initial (day 0) & $0.490 \pm 0.015$ & $(100.0)$ & $0.490 \pm 0.015$ & $(100.0)$ \\
7 & $0.491 \pm 0.029$ & $(100.2)$ & $0.481 \pm 0.050$ & $(98.2)$ \\
14 & $0.471 \pm 0.028$ & $(96.2)$ & $0.452 \pm 0.013$ & $(92.2)$ \\
30 & $0.478 \pm 0.042$ & $(97.5)$ & $0.488 \pm 0.039$ & $(99.6)$ \\
45 & $0.537 \pm 0.011$ & $(109.5)$ & $0.514 \pm 0.012$ & $(105.0)$ \\
60 & $0.535 \pm 0.023$ & $(109.2)$ & $0.515 \pm 0.012$ & $(105.1)$ \\
75 & $0.528 \pm 0.012$ & $(107.7)$ & $0.499 \pm 0.005$ & $(101.9)$ \\
90 & $0.509 \pm 0.007$ & $(103.9)$ & $0.488 \pm 0.020$ & $(99.6)$ \\
\hline Storage at $\mathbf{2 5}^{\circ} \mathbf{C}, \mathbf{6 0} \% \mathbf{R H}$ & & & & \\
Initial (day 0) & $0.490 \pm 0.015$ & $(100.0)$ & $0.490 \pm 0.015$ & $(100.0)$ \\
7 & $0.510 \pm 0.011$ & $(104.1)$ & $0.493 \pm 0.012$ & $(100.6)$ \\
14 & $0.496 \pm 0.010$ & $(101.2)$ & $0.458 \pm 0.015$ & $(93.5)$ \\
30 & $0.512 \pm 0.020$ & $(104.4)$ & $0.504 \pm 0.018$ & $(102.9)$ \\
45 & $0.521 \pm 0.019$ & $(106.4)$ & $0.500 \pm 0.005$ & $(102.1)$ \\
60 & $0.548 \pm 0.014$ & $(111.8)$ & $0.505 \pm 0.018$ & $(103.1)$ \\
75 & $0.511 \pm 0.011$ & $(104.3)$ & $0.500 \pm 0.011$ & $(102.0)$ \\
90 & $0.502 \pm 0.018$ & $(102.5)$ & $0.475 \pm 0.011$ & $(96.9)$ \\
\hline
\end{tabular}

$\overline{\mathrm{RH}}=$ relative humidity, $\mathrm{SD}=$ standard deviation.

*Nominal concentration: $0.50 \mathrm{mg} / \mathrm{mL}$.

tMean concentrations are based on 3 separate samples; the percentage remaining is relative to the initial concentration measured on day 0 . 


\section{References}

1. McCormack PL, Keating GM. Tacrolimus: in heart transplant recipients. Drugs. 2006;66(17):2269-79.

2. Jurewicz WA. Tacrolimus versus cyclosporin immunosuppression: long-term outcome in renal transplantation. Nephrol Dial Transplant. 2003;18 Suppl 1:i7-11.

3. Prograf, tacrolimus for injection $5 \mathrm{mg} / \mathrm{mL}$, tacrolimus immediate release capsules $0.5 \mathrm{mg}, 1 \mathrm{mg}$ and $5 \mathrm{mg}$ [product monograph]. Markham (ON): Astellas Pharma Canada Inc; 2011 Apr

4. Advagraf extended release capsules [product monograph]. Markham (ON): Astellas Pharma Canada Inc; 2007 Jun.

5. Elefante A, Muindi J, West K, Dunford L, Abel S, Paplham P, et al. Long-term stability of a patient-convenient $1 \mathrm{mg} / \mathrm{ml}$ suspension of tacrolimus for accurate maintenance of stable therapeutic levels. Bone Marrow Transplant. 2006; 37(8):781-4.

6. Jacobson PA, Johnson CE, West NJ, Foster JA. Stability of tacrolimus in an extemporaneously compounded oral liquid. Am J Health Syst Pharm. 1997; 54(2):178-80

\section{Mihaela Friciu, MSc}

Research Associate

Sarra Zaraa, MSc

Research Associate

Grégoire Leclair, BPharm, PhD

Associate Professor

Faculty of Pharmacy

Université de Montréal

Montréal, Quebec

\section{Competing interests: None declared.}

Funding: This study was funded by an unrestricted grant from Medisca Pharmaceutique Inc, Montréal, Quebec. The company was not involved in the design or conduct of the study; the collection, management, or interpretation of the data; or the preparation, review, or approval of the manuscript.

Acknowledgements: The authors acknowledge the contribution of Isabelle St-Jean, MSc, for critical reading of this manuscript in advance of submission.

\section{BEST.mis better}

\section{One resource for all types of compounding by pharmacies}

\section{WHAT'S INSIDE?}

- Information for pharmacists, pharmacy technicians, planners, architects, engineers-and others who are involved in decisions or activities that affect compounding

- Guidelines for aseptic compounding, non-aseptic compounding, and compounding which involves hazardous drugs-including radiopharmaceuticals

- Best and leading guidelines on topics such as training planning and designing the physical environment, developing an air quality strategy, cleaning and decontaminating areas, monitoring the environment, garbing and hand hygiene, developing compounding procedures, documenting, and much more-all in only 230 pages

HAVE A SNEAK PEEK OR ORDER AT: WWW.cshp.ca/compounding CSHP MEMBERS PAY A DISCOUNTED PRICE
Canadian Society of Hospital Pharmacists Société canadienne des pharmaciens d'hôpitaux 